\title{
ACTIVIDAD CINEGÉTICA EN EL YACIMIENTO CALCOLIITICO DE LOS PÁRAMOS EN AZNALCÓLLAR (SEVILLA, ESPAÑA): INTERPRETACIÓN TAFONÓMICA DE UN PALEOBASURERO
}

\author{
Hunting activity in the chalcolithic site Los Páramos from \\ Aznalcóllar (Seville, Spain): taphonomic interpretation of a \\ rubbish dump
}

\author{
Eloisa Bernáldez Sánchez y Esteban García-Viñas*
}

Recibido el 20 de diciembre de 2010. Aceptado el 9 de marzo de 2011

Resumen. El hallazgo de 143 restos óseos, correspondientes mayoritariamente al sacrificio de jabalíes y ciervos por los antiguos pobladores del yacimiento Calcolítico de "Los Páramos" (Aználcollar, Sevilla), ha sido interpretado tafonómicamente desde los resultados obtenidos en los estudios bioestratinómicos y tafonómicos realizados en la Reserva Biológica de Doñana (Huelva) y en la Sierra Norte de Sevilla. Las variables que han descrito la estructura, la composición y el estado de conservación de la tanatocenosis de esos ecosistemas han sido utilizadas en la descripción de las características de los paleobasureros antrópicos (Bernáldez 2009; Bernáldez et al. 2006, 2008).

Palabras clave: Bioestratinomía, Tafonomía, Parque Natural Sierra Norte de Sevilla, Edad del Cobre, Calcolítico, Sus scrofa.

Abstract. We analyzed 143 elements principally from wild boars and red deers in the chalcolithic archaeological site "Los Páramos" (Aznalcóllar, Seville). We used for this study the results obtained in biostratinomical and taphonomical researches in Doñana National Park (Huelva) and Sierra Norte de Sevilla Natural Park (Seville) (Bernáldez 2009; Bernáldez et al. 2006, 2008) for understand cultural deposits.

Key Words: Biostratinomy, Taphonomy, Sierra Norte of Seville Natural Park, Copper Age, Chalcolithic, Sus scrofa.

\section{INTRODUCCIÓN}

Los paleobasureros antrópicos son un registro sesgado de la alimentación de las poblaciones humanas debido al comportamiento trófico de nuestra especie. Los procesos de preparación del animal sacrificado, las costumbres de distribución de la carne y la industria ósea, entre otros acontecimientos, producen una gran pérdida de información biológica que no llega a enterrarse y que se puede utilizar como indicador de la actividad que desarrolló el agente productor de los desechos (Tafonomía de la ausencia; Bernáldez y Bernáldez 2003). A esta actividad antrópica suele sumarse los efectos de la acción de otros agentes bióticos y de los procesos fosildiagenéticos físicos, químicos y/o biológicos (Renzi et al. 1975; Fernández-López 2006).

Con el objetivo de describir los efectos producidos por los distintos agentes productores de desechos orgánicos se realizó el estudio bioestratinómico de la tanatocenosis de

* Eloisa Bernáldez Sánchez. Laboratorio de Paleobiologia. Instituto Andaluz del Patrimonio Histórico. Esteban García-Viñas. Dpto. de Sistemas Físicos, Quimicos y Naturales. Facultad de Ciencias Experimentales. Universidad Pablo de Olavide. 
mamíferos en la Reserva Biológica de Doñana (Bernáldez 2002, 2009). Los resultados mostraron la dinámica de formación de un depósito óseo superficial en función, principalmente, de la actividad carnívora carroñera. Este modelo es muy similar al descrito por Behrensmeyer y Boaz (1980) para la tanatocenosis del Parque Nacional de Amboseli (Kenia), de manera que la actividad carnívora carroñera sigue unas pautas muy similares aún en ecosistemas con comunidades faunísticas diferentes.

Las magnitudes y variables empleadas en la descripción de la tanatocenosis natural de Doñana fueron utilizadas en el estudio tafonómico de 12 yacimientos arqueológicos del Holoceno de origen supuestamente antrópico. El resultado nos mostró una dinámica general de conservación muy similar a la de cualquier carnívoro carroñero, encontrando las diferencias en la presencia de especies actualmente domesticadas y en el estado de conservación de los huesos (cortes de carnicería). El hecho que más nos ha llamado la atención es la diversidad de pautas de conservación de los especímenes dentro de esa dinámica general, la cual viene a agrupar los paleobasureros según el grado de preservación de la información original.

Hasta ahora, podemos afirmar que si bien no hay grandes cambios en la variedad de especies consumidas por nuestros antepasados (una variedad que se mantiene en la actualidad) en estos últimos 8.000 años en el SO de Andalucía, sí que los encontramos en las relaciones que mantiene la acumulación de especímenes (huesos, individuos y especies) y el estado de conservación de los mismos en función de la cultura humana, del ecosistema explotado, de las características biológicas de las especies sacrificadas y del mayor 0 menor carroñeo que los humanos practicamos a través de los usos que hacemos de los huesos (industria ósea, metalurgia, cerámica) (Bernáldez 2002, 2009). Quizás una de las variables que mejor define a los humanos, además del manejo de ciertas especies, es la que cuantifica la fragmentación de los huesos con instrumentos manufacturados.

Con el análisis paleobiológico de los restos óseos conservados en las estructuras calcolíticas de "Los Páramos» (Aználcollar, Sevilla) pretendemos definir las condiciones de conservación de dicho depósito y, a partir de éstas, identificar la actividad antrópica que produjo los desechos y al agente (o agentes) enterrador.

\section{EL YACIMIENTO CALCOLÍTICO "LOS PÁRAMOS"}

La intervención arqueológica objeto de estudio se encuentra situada en el paraje denominado "Los Páramos» en el término municipal de Aznalcóllar (Sevilla) (figura 1). En esta zona se individualizaron dos áreas con restos arqueológicos prehistóricos que fueron denominados Poblado Calcolítico y Cista respectivamente (Hunt 2003). Los restos arqueológicos del poblado Calcolítico procedian de ocho estructuras excavadas en margas, seccionadas y expuestas en el talud N. de la carretera Aznalcóllar-Gerena. Sólo en tres de ellas se hallaron restos óseos: UI5, UI9 y UI10,

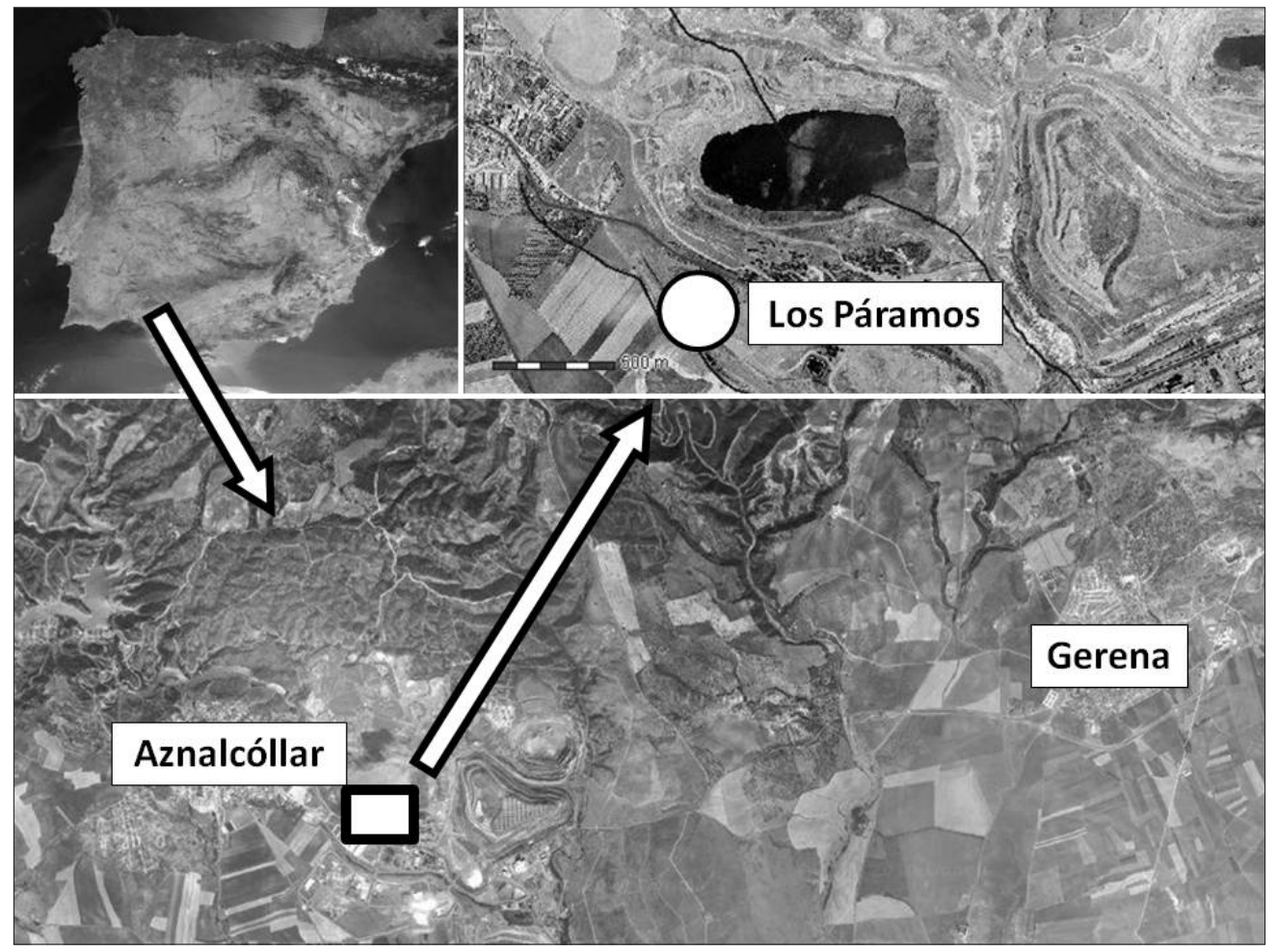

FIGURA 1. Situación aproximada de la intervención arqueológica de "Los Páramos», junto a la carretera que une los municipios de Aznalcóllar y Gerena (Sevilla, España). 
De entre las características ambientales del enclave actual, se puede destacar que el término municipal de Aznalcóllar está situado a 155 m s.n.m. en el valle que separa la comarca de El Aljarafe de la Sierra, una zona que actúa de ecotono entre ambos ecosistemas y donde la riqueza faunística se ve beneficiada por esta condición de frontera ecológica, destacando la presencia de las dos especies silvestres que componen la mayoría de los restos del yacimiento: ciervos y jabalies. Esta última especie es la única de caza mayor que puede abatirse actualmente en la zona y en los siglos pasados (Madoz 1850: 46; Arenas y Carrascal, 2004: 75).

Por su parte, los espacios naturales que mencionamos y los yacimientos arqueológicos estudiados están descritos en Bernáldez (2009) y en Behrensmeyer y Boaz. (1980).

\section{METODOLOGÍA}

\subsection{El análisis de la tanatocenosis de Doñana y Sierra Norte de Sevilla}

Las asociaciones de cadáveres producidos en los ecosistemas actuales son objeto de estudio del grupo de investigadores del IAPH. El objetivo del estudio bioestratinómico de los depósitos óseos actuales ha sido identificar la actividad carnívora carroñera mediante unas magnitudes y variables que describieran la acumulación de huesos y el estado de conservación de los mismos producidos por agentes bióticos no humanos (Bernáldez 2002, 2009; Bernáldez et al. 2008).

La acumulación de especímenes se mide por la riqueza faunística o número de especies presentes (NSP), por el número de cadáveres (NMI) y el número de huesos por especie (NH). El estado de conservación del depósito se mide por el porcentaje de especies con más de $50 \mathrm{~kg}$ presentes respecto al total de la comunidad actual, por el porcentaje de huesos conservados por especie o Índice de Conservación Esquelética (ICEn $=\mathrm{NH} \times 100 / \mathrm{NE} \times \mathrm{NMI}$, donde $\mathrm{NH}$ es el número de huesos, NE el número de huesos del esqueleto y NMI el número mínimo de individuos estimado), por las partes anatómicas preservadas (ICEn de cabeza, tronco y extremidades) y por el Índice de Fragmentación de los huesos que explicaremos en el apartado siguiente.

De todas las conclusiones obtenidas en el estudio bioestratinómico de Doñana (Bernáldez 2009) y de Amboseli (Behrensmeyer y Boaz 1980) seleccionamos aquéllas que nos permiten interpretar tafonómicamente los depósitos de huesos de las estructuras arqueológicas de "Los Páramos».

- La presencia de una especie de vertebrado en un depósito de cadáveres superficial depende de la fauna carnivora y carroñera que conserve el ecosistema y ésta actúa en función de la masa corporal del cadáver, del tamaño de la población, de la edad del individuo, del biotopo en el que haya vivido, de los eventos estacionales y ocasionales y de la etología de la especie muerta. La tendencia general de conservación de los esqueletos carroñeados es que todas las especies con más de $50 \mathrm{~kg}$ están presentes en la tanatocenosis superficial, siendo muy escasa la presencia del resto de las especies. Estas tanatocenosis están compuestas en más de un $70 \%$ de individuos muertos por enfermedades que serán carroñeados (algunos cadáveres escapan de la actividad carroñera debido a acontecimientos físicos como los aluviones de barro).

- Aún cuando las especies tengan más de 50 kg, los jóvenes no suelen permanecer el tiempo suficiente sobre la superficie para que la vegetación y los procesos geofísicos los entierren. Éstos son rápidamente depredados o permanecen en superficie más o menos tiempo según la masa corporal y la edad del animal.

- Las especies con más de $50 \mathrm{~kg}$ están representadas por un número de cadáveres que está en función de la masa corporal, del tamaño de la población y de la tasa de mortandad ocasional o estacional de cada especie (epidemias y épocas de celo). Las especies más pequeñas suelen ser de mayor tamaño poblacional y producen más cadáveres, sin embargo, no por ello hallamos más restos, ya que son carroñeados en menos tiempo.

- El porcentaje de huesos esparcidos por la superficie que llega a enterrarse suele ser del 5 \% según Behrensmeyer y Boaz (1980) y, además, no todos los huesos tienen la misma probabilidad de conservación, el cráneo suele ser la parte anatómica más resistente y la que mayor probabilidad tiene de formar parte de una tafocenosis.

- El seguimiento de los procesos postmorten de más de 30 cadáveres en Doñana y en la sierra demuestra que cuanto más pesa un cadáver, más tiempo se conserva (parcialmente) sobre la superficie debido a la resistencia que presenta al carroñeo. Con el tiempo, las condiciones geofísicas y la vegetación producen el enterramiento de muchas de estas piezas (el $5 \%$ que estiman Benhrensmeyer y Boaz 1980). De esta manera aumentan las probabilidades de una especie para estar mejor representada en una tafocenosis, estas probabilidades cambian cuando existe un enterramiento inmediato sin huellas de carroñeo ni de exposiciones.

Hay otros factores, de menor efecto, que condicionan la formación de un depósito de desechos, estos serán utilizados en la interpretación de alguna de las especies tratadas en este estudio.

\subsection{Estudio de la tafocenosis de «Los Páramos»}

La interpretación tafonómica y paleobiológica de este yacimiento parte de los resultados obtenidos en la descripción de la composición y estructura de la tafocenosis y en la 
cuantificación del estado de conservación de los animales sacrificados, de las partes anatómicas y de los huesos.

Para la determinación del material óseo contamos con las colecciones de referencia del Instituto Andaluz del Patrimonio Histórico y de la Estación Biológica de Doñana (CSIC), además de la bibliografía especializada (Schmid 1972, Barone 1999, Popesko 1998 y Wilkens 2003). Las características biológicas de las especies en cuanto a talla, edad, sexo y patología han sido utilizadas para interpretar las pautas del comportamiento trófico de quiénes produjeron estos desechos $y_{1}$ en lo posible, las condiciones del paleoecosistema. Este estudio del contenido se completa con el análisis de la distribución espacial de los restos dentro de cada estructura.

Las variables usadas para medir la acumulación de especímenes son las densidades de individuos y de masa ósea registrada, variables que consideran el volumen diferente de cada estrato o de cada yacimiento. Al número de elementos o de restos NR no lo consideramos una medida de la presencia de cada especie sino que lo es del estado de conservación de los huesos debido a la actividad industrial y trófica de los humanos (Bernáldez 2002). La expresión que mide el estado de fragmentación de los huesos es Log (NRT/NH), siendo NRT el total de especímenes o restos óseos y $\mathrm{NH}$ el número de huesos identificables y medibles. La segunda variable de conservación estima el porcentaje de huesos o la masa ósea estimado en función del total de huesos y masa de los esqueletos completos de cada especie (para esta última hay que considerar la diferencia de masa corporal según la edad de los individuos), la expresión que utilizamos es el Índice de Conservación Esquelética (ICEn). Desde esta variable se cuantifica la pérdida de información biológica de cada individuo sacrificado y de cada parte anatómica.

Las relaciones estadísticas de las variables de acumulación y conservación definen la dinámica de formación y preservación del depósito, ésta será comparada con las de otras tafocenosis estudiadas (Bernáldez, en prensa). Hasta ahora, los yacimientos arqueológicos estudiados con esta metodología han presentado una dinámica general que se diversifi- ca según el período cultural, el ecosistema explotado, la función antrópica a la que se destinó el depósito y la fragmentación de los huesos (Bernáldez 2009).

\section{TAFOCENOSIS DEL POBLADO CALCOLÍTICO DE «LOS PÁRAMOS»}

\subsection{Composición y estructura de la tafocenosis}

Se han analizado 143 restos óseos que suman una masa de $775 \mathrm{~g}$ pertenecientes a un mínimo de cuatro individuos de Sus scrofa', dos de Cervus elaphus (ciervo), uno de Canis familiaris (perro) y uno de Oryctolagus cuniculus (conejo). Aunque este escaso material se conservaba en tres estructuras (UI 5, 9 y 10), sólo analizaremos tafonómicamente la UI 9 por ser la única que conservaba una estratigrafía completa (Hunt 2003) y la mayor parte de los restos estudiados; contiene el 77,7\% de los individuos, el 97,3\% de la masa ósea y el $96.5 \%$ de los elementos (113 especímenes óseos, $747 \mathrm{~g}$ y seis individuos), procedente, al menos, de tres suidos (Sus scrofa), un cérvido (Cervus elaphus), un cánido (Canis familiaris) y un lagomorfo (Oryctolagus cuniculus). De ellos, los suidos son el grupo zoológico mejor representado por 95 elementos (84 \% del total) con $632 \mathrm{~g}$ (84.61\% de la masa total) y tres de los seis individuos estimados (Tabla 1).

Este registro óseo se hallaba en el interior de la mitad de esa estructura UI9 circular y acampanada excavada en la marga (figura 2) con 1,5 m de diámetro y 0,86 m de potencia desde el nivel de marga (hemos perdido el suelo del período Calcolítico). En referencia a la capacidad del «hoyo" $\left(0,76 \mathrm{~m}^{3}\right)$ como observamos en la figura 2 se conserva un número muy escaso de huesos para que consideremos esta estructura como un contenedor de desechos orgánicos, si bien es cierto que junto a estos huesos, los arqueólogos haIlaron abundante material cerámico (desconocemos la función de estos hoyos, si fueron silos, cabañas, zonas de compostaje...). Los restos se han conservado en una matriz

TABLA 1. Material faunístico registrado en "Los Páramos» en base al número de elementos (NE), a la masa (M, gramos) y al número de individuos (NMI)

\begin{tabular}{|c|c|c|c|c|c|c|c|c|c|c|c|c|c|c|c|c|c|}
\hline \multirow{3}{*}{ Estrato } & \multicolumn{17}{|c|}{ Especie } \\
\hline & \multicolumn{3}{|c|}{ Sus. s. } & \multicolumn{3}{|c|}{ Cervus e. } & \multicolumn{3}{|c|}{ Canis $f$. } & \multicolumn{3}{|c|}{ Oryctolagus c. } & \multicolumn{2}{|c|}{ Indeterminado } & \multicolumn{3}{|c|}{ Total } \\
\hline & $\mathrm{NE}$ & $M$ & NMI & $\mathrm{NE}$ & $M$ & NMI & $\mathrm{NE}$ & $M$ & NMI & $\mathrm{NE}$ & $M$ & NMI & $\mathrm{NE}$ & $M$ & $\mathrm{NE}$ & $M$ & $\mathrm{NMI}$ \\
\hline UI 5 / UE 2 & & & & 2 & & 1 & & & & & & & 1 & 1 & 3 & 1 & 1 \\
\hline UI 9 & 95 & 632 & 3 & 3 & 110 & 1 & 14 & 4 & 1 & 1 & 1 & 1 & 24 & 8 & 137 & 755 & 6 \\
\hline UI 10 / UE 6 & 3 & 19 & 1 & & & & & & & & & & & & 3 & 19 & 1 \\
\hline & & & 4 & 5 & & 2 & & 4 & 1 & 1 & 1 & 1 & & 9 & & & 8 \\
\hline
\end{tabular}

Los datos se encuentran clasificados por especie (Sus scrofa, Cervus elaphus, Canis familiaris, Oryctolagus cuniculus), destacando Sus scrofa por ser la mejor representada y la unidad de intervención 9 por ser la que presenta los valores más altos de acumulación.

1 Las características anatómicas de estos individuos son iguales a las observadas en los actuales jabalíes de la Sierra Norte de Sevilla y difieren de las de los cerdos actuales, El estudio del ADN antiguo podría ayudar a solucionar esta cuestión, teniendo en cuenta que ambas formas, la silvestre y la domesticada, son la misma especie a pesar de las grandes diferencias anatómicas que podemos observar en la actualidad. 
FIGURA 2. Imagen de la estructura intervenida en la UI 9. Se puede observar la disposición de algunos restos óseos. (Foto cedida por el Dr. Marc Hunt).
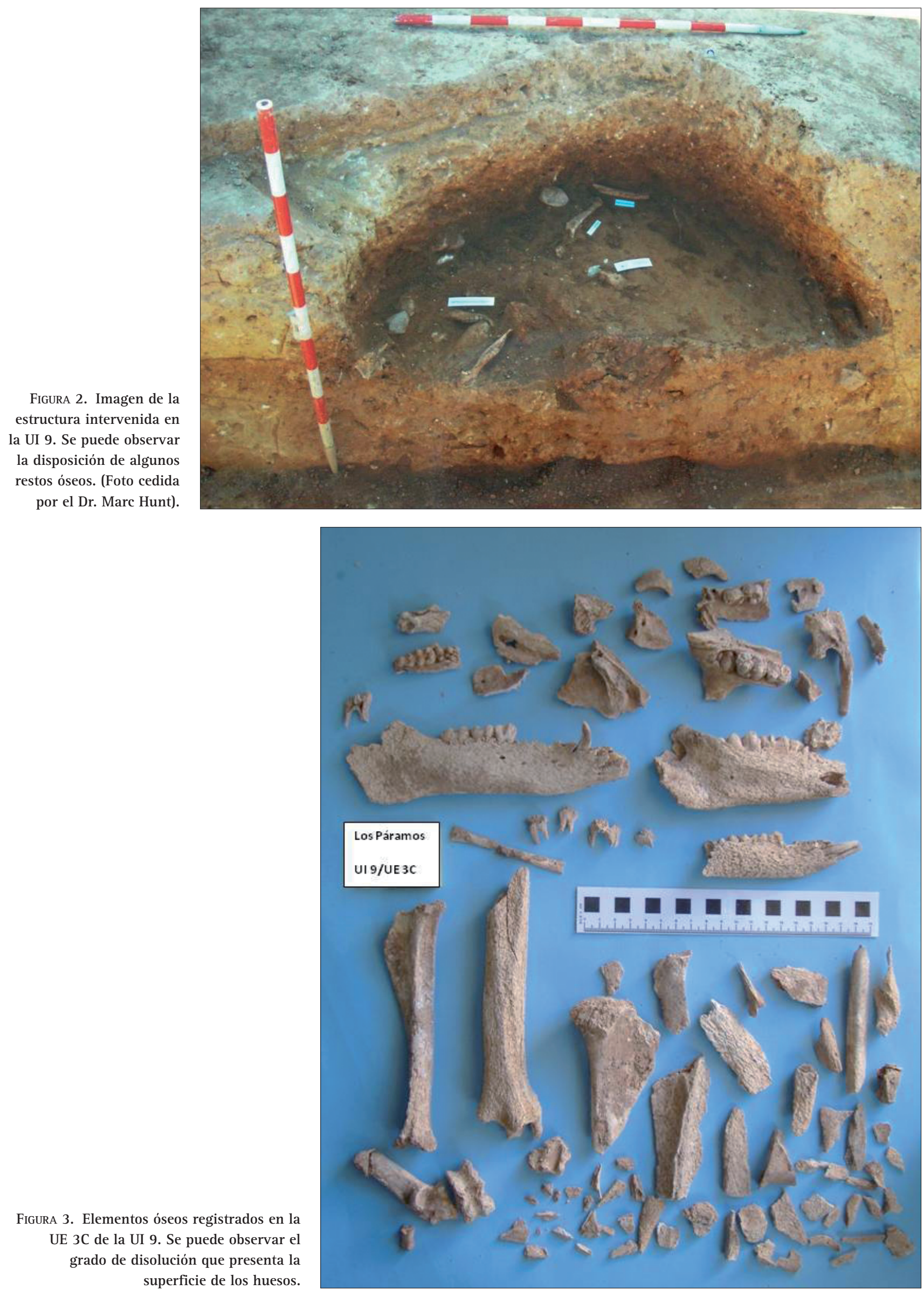

๑ UNED. Espacio, Tiempo y Forma. Serie I, Nueva época. Prehistoria y Arqueología, t. 3, 2010. 
terrosa de suelos cambisoles crómicos (los suelos más abundantes de la Sierra Norte de Sevilla) cuyas características explicarán el estado de conservación de la superficie de los huesos (figuras 3 y 4 ).

De esta variedad faunística registrada en la UI9 observamos que hay una selección entre todas las que podrían ser

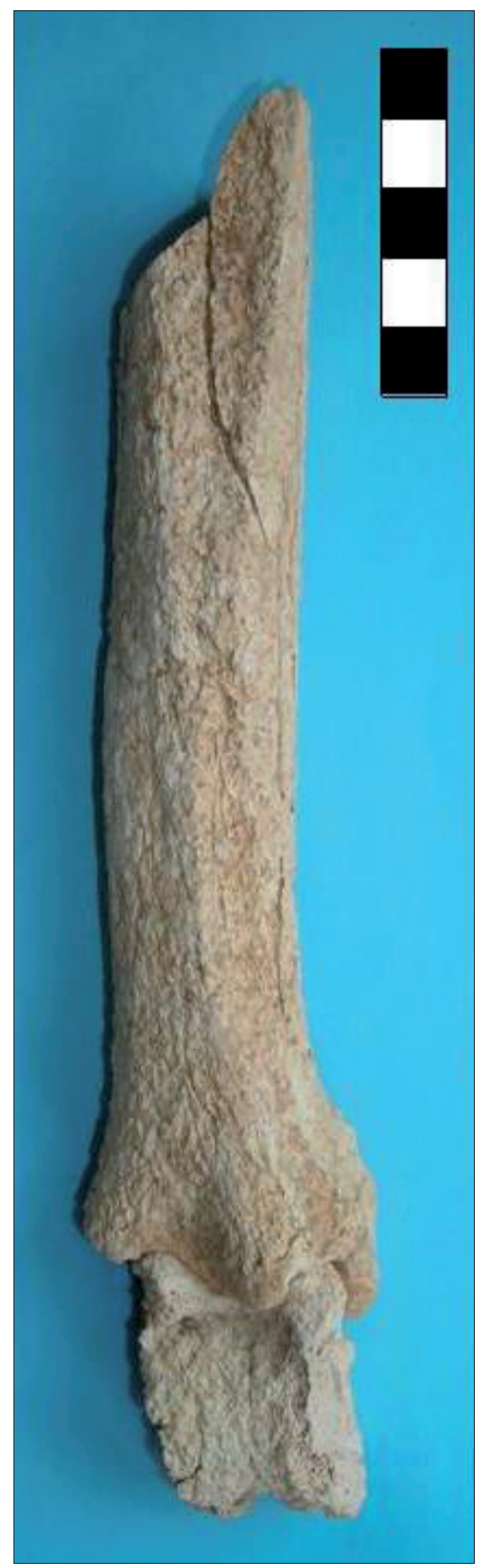

FIgURA 4. Epífisis distal de tibia de ciervo en relación con un astrágalo. Se pueden observar marcas de corte en la diáfisis de la tibia y como la epífisis distal de la misma se encuentra fusionada, implica que la edad del individuo es superior a los dos años y medio de vida. sacrificadas. Atendiendo a los resultados de Doñana antes expuestos, si el agente productor no fuese selectivo deberíamos encontrar restos de todas las especies con más de 50 $\mathrm{kg}$, algunas de mesocarnívoro y un lagomorfo, el resultado es que tenemos dos especies de masa superior a los $50 \mathrm{~kg}$ (ciervos y jabalies), un mesocarnívoro (perro) y un lagomorfo (conejo). Esta asociación es muy similar, en cuanto a los grupos zoológicos representados, a la producida por la actividad carnívora carroñera de un ecosistema mediterráneo como el de Doñana, pero difiere en la representación sesgada de las especies con más de $50 \mathrm{~kg}$; las vacas, caballos, cerdos y caprinos, entre las especies domesticadas, y los uros, caballos, cabras monteses, osos y lobos machos, entre las silvestres.

De la presencia de ciervos y jabalies en esta estructura UI9 (y en las otras dos) deducimos la actividad cinegética desarrollada por los pobladores de "Los Páramos», al menos, en esta ocasión. Las dos especies con menos de $50 \mathrm{~kg}$, el perro y el conejo, podrian estar presentes por el carácter intrusivo de los conejos (Montón 1999) (las madrigueras tienen un metro de longitud y suelen ser limpiadas cada año de cadáveres por los propios conejos, quedando algunos huesos enterrados en ese proceso) y por el enterramiento intencionado del perro. La conservación de 14 fragmentos de costillas de este animal demuestra que fueron enterradas, de permanecer en superficie hubiesen sido inmediatamente carroñeadas.

La conservación de huesos en conexión como la tibia y el astrágalo de un ciervo muestran que estos huesos estaban conectados cuando se enterraron.

\subsubsection{Tamaño de las poblaciones}

Esta selección de jabalies y ciervos para el consumo no implica una actividad cinegética muy especializada, ya que estos pobladores están cazando las poblaciones más abundantes de ungulados, que aún en la actualidad son las principales piezas en las monterias (Garde et al. 2010; Azorit y Moro 2010).

Las actuales densidades de ciervos y jabalíes varían según los ecosistemas. En los censos de 1995 en el Parque Nacional de Doñana el número de jabalies era de unos 1700, mientras que la población de ciervos no sobrepasaba los 500 ejemplares (Fernández-Llario 1996; Ministerio de Medio Ambiente 2004), es decir, que entre ambas poblaciones la relación de individuos era de $3: 1$, el mismo ratio que la encontrada en la UI9.

Sin embargo, hemos de mencionar que normalmente las proporciones de estas dos especies en la última década de Doñana son inversas, es decir, que las densidades de ciervos suelen ser hasta tres veces superiores a las de los jabalies (datos de la Reserva Biológica de Doñana²), y también que las

\footnotetext{
"Datos del Equipo de Seguimiento de Procesos Naturales de la Estación Biológica de Doñana" (http://wwwrbd.ebd.csic.es/Seguimiento/mediofisico.htm).
} 
FiguRA 5. Comparación de dos hemimandíbulas de Sus scrofa con un premolar decidual $\left(\mathrm{m}^{3}\right)$,

la situada a la izquierda de la

imagen pertenece a "Los

Páramos" y la que se encuentra a la derecha corresponde a un individuo de unos nueve meses del Parque Natural de la Sierra Norte de Sevilla.

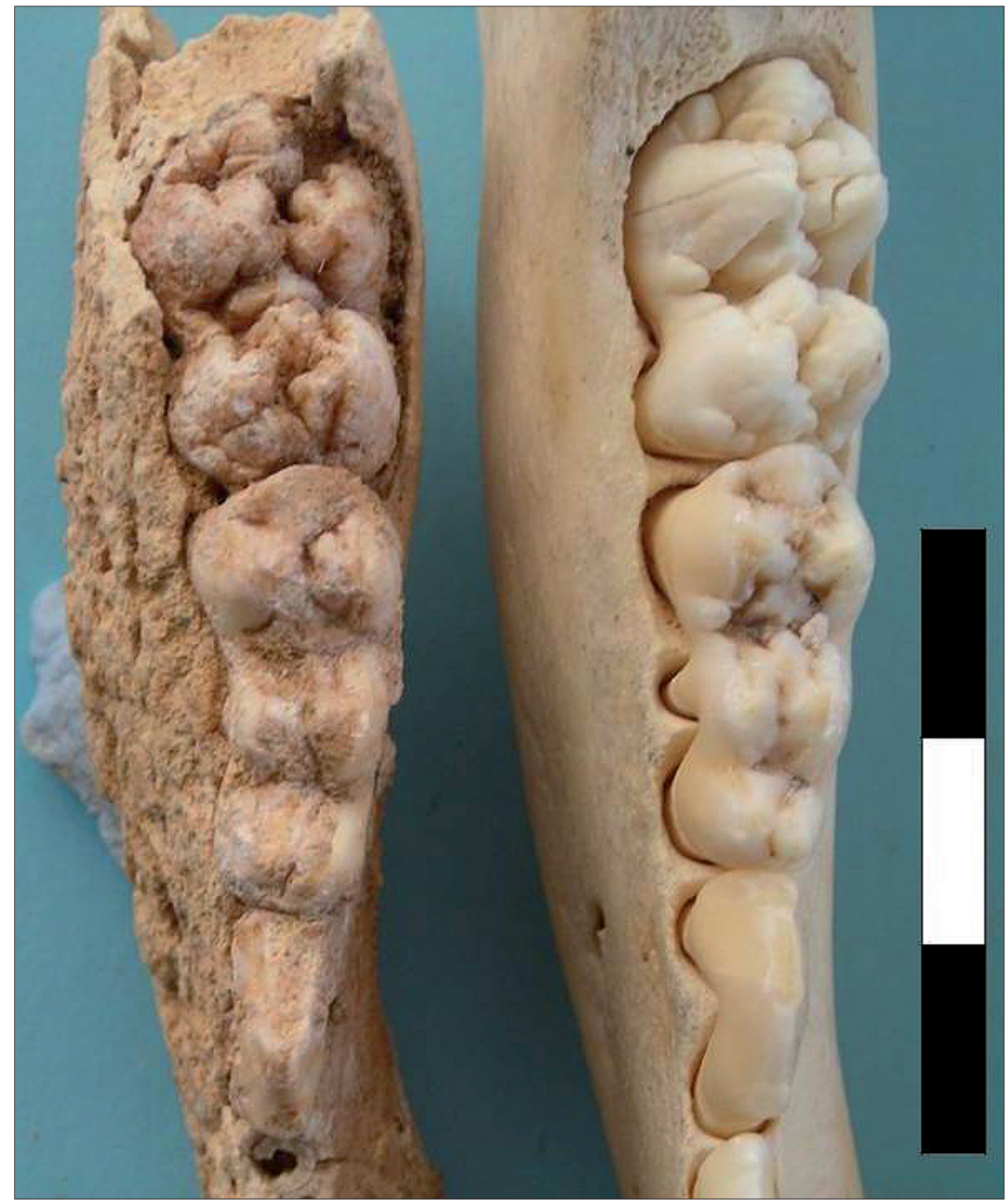

proporciones de animales cazados suele ser superior para los ciervos. Garde et al. (2010) contabilizaron más de 60.000 ejemplares cazados cada año en España y Azorit y Moro (2010) sumaron unos 25.000 jabalíes (esto puede no estar en relación con la abundancia de cada especie).

Es tan escasa la muestra que tenemos que no podemos concluir que los cazadores de este poblado lo hacian en proporción a los tamaños de las poblaciones de ambas especies durante el período Calcolítico.

Independientemente de los valores de los censos actuales (que varian según los métodos utilizados) y de las monterías, la biología reproductiva de ciervos y jabalies favorece a esta última especie. Mientras que las ciervas suelen parir un ejemplar por año, cuando hay alimentos suficientes, las jabalinas paren siempre más de dos jabatos. Esto implicaría una población silvestre más abundante de jabalies que de ciervos y una actividad cinegética oportunista en la que se caza de lo que más abunda.

\subsubsection{Estructura de edad}

En la estructura de edad de las poblaciones actuales abundan los jóvenes, al menos en el período de nacimientos, para los ciervos la época de nacimientos está entre mayo y julio, mientras que los jabalies suelen nacer entre febrero y abril, aunque según algunos autores pueden parir casi durante todo el año (Rosell et al. 2001). El rango de edad de los jabalíes sacrificados en "Los Páramos" es inferior a los dos años y medio, para Davis (1989) la presencia de juveniles identificaría la matanza de individuos domesticados. Según Rosell et al. (2001) el 79 \% de las poblaciones de jabalies en Europa no supera los dos años y medio de edad, si esto es así, estos cazadores estarían sacrificando la parte de la población más abundante, la que tiene menos de dos años y medio, y además no están abatiendo cualquier edad dentro de este rango.

Se ha analizado el estado de fusión de las epífisis de los huesos (Schmid 1972; Barone 1989) y de erupción de los 


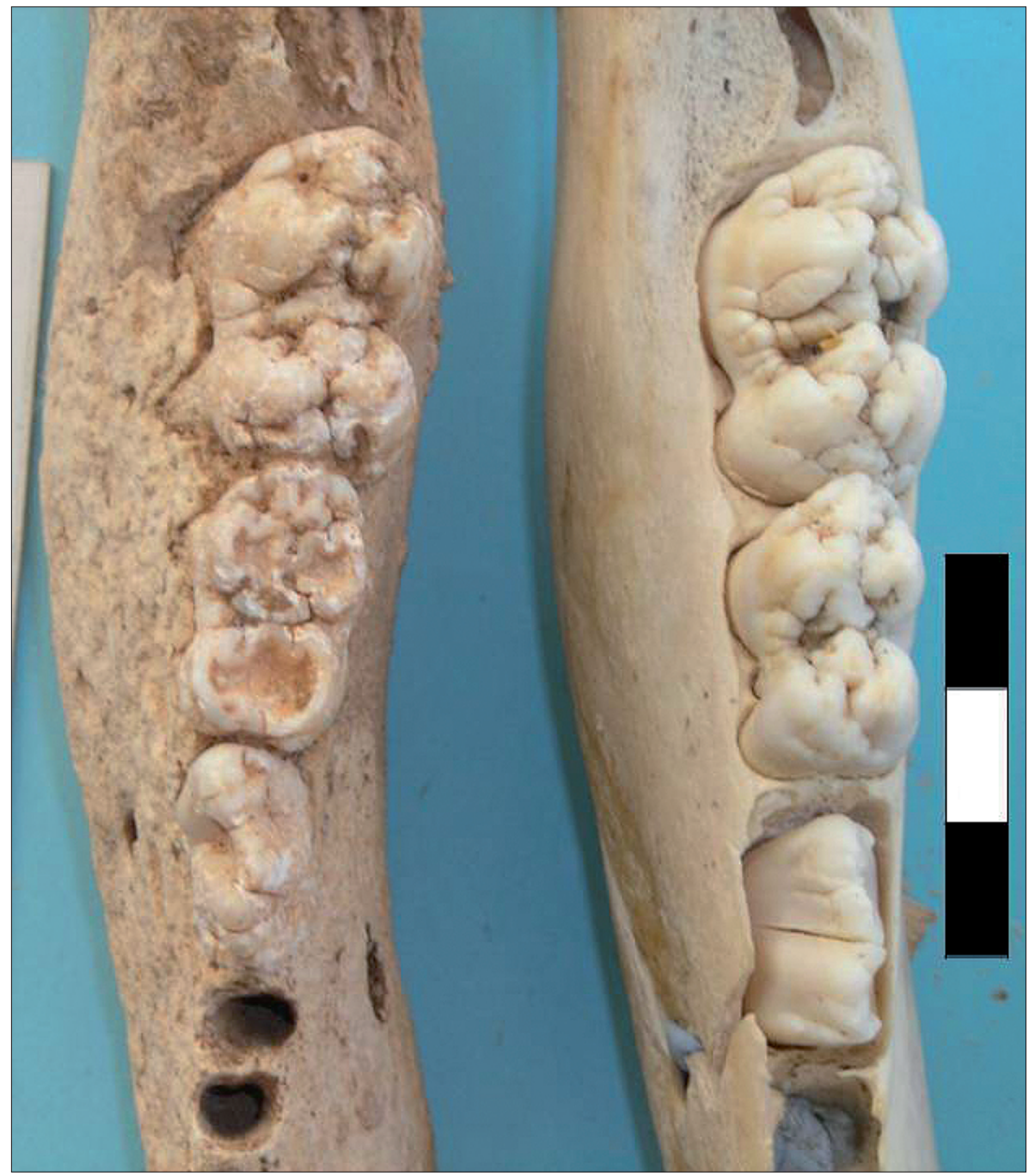

FIgURA 6. A la izquierda de la imagen se observa una hemimandíbula derecha de Sus scrofa rescatada en el yacimiento arqueológico de «Los Páramos», en la parte derecha se encuentra la misma pieza, en este caso perteneciente a un individuo actual del Parque Natural de la sierra Norte de Sevilla.

dientes (Schmid 1972) para determinar la edad aproximada de los individuos enterrados en "Los Páramos». Los tres ejemplares de Sus scrofa registrados en la estructura UI9 presentan edades diferentes a partir del estudio de la dentición. Uno de ellos tiene los premolares P3 y P4, es decir, que tiene más de 12 meses, como aún conserva el molar decidual, este animal murió antes de cumplir los 14 meses (figura 5); el segundo de ellos presenta una dentición que se corresponde con un rango de edad superior a los 14 meses e inferior a los 18 meses (figura 6) según el premolar P4 y la ausencia del molar M3 (sale a partir de los 18 meses) y el tercer ejemplar tenía más de 18 meses y posiblemente más de dos años al presentar toda la dentición con cierto desgaste, el molar M3 comienza la erupción a los 18 meses y termina a los tres años.

También se estudió la edad de los individuos atendiendo al estado de fusión de la epífisis distal de tibia y de la tuberosidad calcánea (figura 3). Este análisis nos lleva a estimar que uno de los individuos (rescatado en la UI 9) tenía, al menos, dos años de vida.
Este espectro de edad de sacrificio, que como ya se mencionó podría responder al sacrificio de individuos domesticados por los humanos, es aproximadamente el mismo que observamos en las actuales monterías de la Sierra Norte de Sevilla. Este rango de edad no es fácilmente detectable durante una cacería, el pelaje de todos ellos habría cambiado al de adultos a partir de los 10 a 12 meses, por lo tanto los cazadores tan sólo detectarían diferencias de tallas. Dos de ellos tendrían un tamaño muy próximo a un adulto (entre 60 y $70 \mathrm{~kg}$ ) y el tercer individuo sí que podría no sobrepasar los $30 \mathrm{~kg}$ de masa corporal. Además, la presencia de estos tres jabalies puede estar representando a una piara (Blanco 1998; Étienne 2004), que según Rosell et al. (2001) son de tres a cinco ejemplares, bien de una hembra con sus crías de dos camadas o bien de jóvenes machos.

Así como son escasos los huesos conservados en "Los Páramos", también son escasos los huesos medibles para estimar la talla de los animales sacrificados. Las medidas de un calcáneo de jabalí de la UI9 están en el límite superior de la asociación de suidos conservados en el yacimiento Calcolíti- 
co de "La Gallega" de Valencina de la Concepción situado a 17 km de "Los Páramos", de los que desconocemos si son silvestres o domesticados (se analizará el ADN antiguo a pesar de que ciertos autores no han encontrado muchas diferencias genéticas que aclaren estas condiciones). Mientras que las de un astrágalo de esta misma especie muestra una altura similar a los suidos de "La Gallega», pero una anchura (Ad) de la epífisis distal inferior a éstos, es decir, que sería un animal más grácil. Ambas piezas anatómicas, el calcáneo y el astrágalo son del mismo lado del cuerpo y podrían ser de un único individuo, la diferencia de talla se debía al grado de erosión química del astrágalo.

El análisis estadístico de los astrágalos de varias asociaciones de suidos encontrados en distintos yacimientos junto con los de los actuales jabalíes de Ucrania (los más grandes de Europa) mostró tres grupos de individuos con diferencias significativas en la longitud del mismo (Lla, $p=0.00007 ; R^{2}=$ $0.41 ; \mathrm{SE}=0.117 ; \mathrm{CC}=-0.637$ ), siendo los más grandes los jabalies actuales de Ucrania, seguido por los del Calcolítico; los más pequeños son los de los yacimientos más modernos del SO de la Península Ibérica ${ }^{3}$ (Bernáldez 2010).

\subsection{Estado de conservación del depósito}

\subsubsection{Estado de conservación de los individuos}

El ICEn o porcentaje de huesos conservados del total del esqueleto de cada individuo enterrado es inferior al $5 \%$ (Bernáldez 2009), un dato que coincide con el porcentaje de huesos que se entierran procedentes de un cadáver que permanece en superficie expuesto a la actividad carroñera según Behrensmeyer y Boaz (1980); pero también es el porcentaje medio de huesos que venimos registrando en los yacimientos arqueológicos de origen antrópico. Es decir, que este índice no tiene un carácter diferenciador entre las distintas especies carnívoras y carroñeras, sino más bien es un dato que nos une a este grupo de animales. Exactamente hemos encontrado en la UI9 el 3.71\% de los huesos de los tres jabalies (30 huesos de los 807 huesos de los esqueletos completos) y el $1.46 \%$ de los del ciervo (3 huesos de los 205 del esqueleto completo).

Si fueron enterrados inmediatamente como demuestra la superficie de los huesos que no presentan líneas de fractura debidas a la exposición del sol (Behrensmeyer 1978), ¿dónde están el resto de los huesos del esqueleto de los jabalies y del ciervo?

\subsubsection{Estado de conservación de las partes anatómicas}

En cuanto a las partes anatómicas mejor conservadas, tenemos que los jabalíes conservan el $20.37 \%$ de los huesos de la cabeza ( 11 huesos de 54 de los tres individuos); el $1.45 \%$ de los huesos del tronco (4 de un total de 276 ) y el $3.14 \%$ de los de las extremidades (15 huesos de los 477). También en Doñana la parte anatómica que permanece más tiempo en la superficie es el cráneo. En el seguimiento de tres individuos de la reserva encontramos que después de dos años de la muerte del animal aún permanecía el $2.5 \%$ de los huesos de las extremidades, el $7.6 \%$ del tronco y el $100 \%$ de la cabeza, otro que murió cuatro meses antes conservaba el $22.6 \%$ de las extremidades, el $3.3 \%$ del tronco y el $94.4 \%$ de la cabeza y finalmente, uno que murió hacia 15 meses registraba el $1.9 \%$ de las extremidades, el $8.7 \%$ del tronco y el $100 \%$ de la cabeza. En cualquier caso, todos conservaban el cráneo después de dos años de exposición a los carroñeros, mientras que el resto del esqueleto experimentaba una gran pérdida de huesos. El estado de conservación de los tres jabalíes de "Los Páramos» podría explicarse por la actividad carroñera, si no fuese por la ausencia de líneas de exposición en la superficie de los huesos y los cortes de carnicería. De modo, que estamos ante una importante ausencia de huesos de los ungulados de manera intencionada, el agente productor de ese depósito ha carroñeado gran parte de los esqueletos o han transportado los huesos a otro lugar, quedando en el depósito las partes anatómicas poco rentables o las que consumieron estos cazadores.

\subsubsection{Estado de conservación de los huesos}

Si en este lugar se conservaron tan pocos restos de los animales cazados es posible que enterrasen los desechos del consumo y el resto del animal se trasladó a otro lugar. Las partes anatómicas que registramos en los jabalies se corresponden con huesos con un bajo beneficio cárnico (Bernáldez 2009) que suelen ser desechados durante la preparación de los animales sacrificados en los mataderos, pero también hemos encontrado huesos de las extremidades (el jamón y la paletilla) de uno de los ejemplares; es decir, prepararon las piezas y consumieron una parte de ellas.

En este período del Calcolítico solemos hallar un alto grado de fragmentación de los huesos, sin embargo, el Índice de Fragmentación Log (NRT/NH) en "Los Páramos» es de 0.37 (48 huesos entre los 113 fragmentos óseos de la UI9). El único caso que tenemos para interpretar este dato es el

3 El primer grupo lo conformaban las medidas de los jabalies actuales de Polonia. El segundo grupo estaba formado por los individuos de los yacimientos calcolíticos de "La Gallega» en Valencina de la Concepción, "Amarguillo» en Utrera (Cabrero et al. 2006; Bernáldez 2009) con datación por C14 en el 2500 a.C. y «Cerro de Capellania» en Vélez Málaga (Bernáldez 2009). El tercer grupo lo componian los huesos encontrados en los yacimientos orientalizantes de la "Calle Alcazaba» de Lebrija (Bernáldez y Bernáldez 1999) y de la "Calle Costanilla» en Carmona, junto a los niveles romanos de la "Calle Alcazaba» de Lebrija, los del siglo XVI de las «Reales Atarazanas» de Sevilla (Bernáldez y Bernáldez 1997), de los estratos del siglo XVII de "Puerto Real» en el Caribe y los del nivel del siglo XII del "Castillo de San Jorge» de Triana en Sevilla. 
obtenido en un paleobasurero de la "Calle Alcazaba" de Lebrija (Bernáldez y Bernáldez, 1999), una sucesión de desechos que va desde el VI milenio a. C. hasta la Edad Media. Los valores superiores del índice de fragmentación eran de 1.38 para los niveles más antiguos de ese yacimiento del VI milenio a. C., de 0.75 hasta el III milenio a. C. e inferior a 0.55 a partir de los niveles del Bronce, un valor que desciende hasta 0.37 en el nivel Roma-Edad Media. La interpretación de estos valores es que en los niveles más antiguos los huesos estaban más fragmentados, disminuyendo esta actividad en los yacimientos más modernos (Correlación de Pearson; $p$-valor =0,0009; $r=0,902 ; g l=8$ ).

En "Los Páramos» tenemos un valor de 0.37 , es decir, que la fragmentación de huesos es inferior al estimado para el Calcolítico de Lebrija y similar al estimado en el nivel Roma-Edad Media. Insistimos que tenemos un escaso número de huesos y de estructuras por lo que no podemos llegar a una discusión científica, pero podríamos decir que el agente productor del depósito no fragmentó los huesos tanto como hemos encontrado en la "Calle Alcazaba" de Lebrija, posiblemente porque estos cazadores despiezaron las presas y consumieron una pequeña parte de ellas (carrillada, jamón y paletilla de los suidos y parte de la extremidad trasera del ciervo), sin interés alguno en reciclar los huesos para otros usos como hemos observado en otros yacimientos del Calcolítico.

Quizás el aspecto más llamativo es el estado de la superficie de los huesos (figura 2) pues presentan una pérdida de materia debido a una actividad química. Los análisis físico-químicos nos cuantificarán los cambios de composición y estructura, mientras tanto consideramos oportuno mencionar el tipo de suelo en el que se han conservado los huesos desde hace más de 5.000 años, es un suelo cambisol crómico que suele formar cárcavas de disolución en las formaciones edáficas, cuanto más en los huesos, debido a un pH ligeramente ácido. Este suelo es el que compone la cobertura edáfica de la Sierra Norte de Sevilla donde la vegetación mejor adaptada es la de encinas y alcornoques (propia para la fauna cazada) y no olvidemos que "Los Páramos» está en las estribaciones de esta formación.

\subsection{Dinámica de conservación del depósito.}

El análisis comparado de las densidades de cadáveres presentes en la tafocenosis de "Los Páramos" y en las tanatocenosis de Doñana y de la Sierra Norte de Sevilla (DI en la UI9 = 7'87 ind $/ \mathrm{m}^{3}$, en Doñana $=2^{\prime} 8 \times 10^{-7} \mathrm{ind} / \mathrm{m}^{3}$ y en Sierra Norte $=1^{\prime} 3 \times 10^{-6}$ ind $/ \mathrm{m}^{3}$ ) apoyan la adscripción de esta UI como depósito antrópico porque la concentración de cadáveres por unidad de volumen supera hasta en 6.000 veces la registrada en los espacios naturales estudiados. Se realizó además un análisis estadístico de correlación de Spearman entre la masa corporal de los individuos registrados y las magnitudes de conservación (ICEn, ICEm) y acumulación (NR, NMI, M). Los resultados sólo revelaron una correlación positiva entre el ICEn y el NE (Rho de Spearman 0.975; sig. 0.005) que podemos interpretar como que las mayores acumulaciones de huesos se corresponden con los esqueletos menos carroñeados, en este caso han sido los jabalíes los que mejor están representados en este depósito, posiblemente porque fueron cazados para abastecer de carne al poblado, pero también sirvieron para el consumo de estos cazadores, por ello encontramos más huesos.

\section{CONCLUSIONES Y DISCUSIÓN}

El yacimiento arqueológico de "Los Páramos» presentaba tres unidades de intervención con restos de fauna, de estás, sólo la UI 9 fue excavada convenientemente para realizar el cálculo del volumen, puesto que las unidades de intervención 5 y 10 fueron seccionadas en su mayor parte por zanjas. Este hecho hace que no se pueda realizar un estudio comparativo de las tres estructuras, resultando la UI 9 la más idónea para su interpretación tafonómica al encontrarse completa en su mitad este.

La cantidad de restos encontrados no colmatan la estructura en la que se encontraron (figura 2), no parece que fuese un basurero orgánico, al menos, tal como lo entendemos como estructura de desechos del consumo. Los restos presentan una superficie con erosión química, pero sin grietas de exposición, de lo que se deduce que estos huesos fueron inmediatamente enterrados, sobre todo, porque hallamos huesos en conexión como la tibia y el astrágalo de ciervo. Algunos de ellos presentan marcas de corte (como la diáfisis de tibia de Cervus elaphus; figura 4) que señala a los humanos como el agente productor del depósito. Según estas características y la estratigrafía podríamos estar ante un depósito antrópico realizado, posiblemente, en un sólo momento tras el abandono de la estructura, ya que la acumulación se da casi en el fondo de la estructura UI 9 como observamos en la figura 7.

La mayoría de los tafones encontrados forman parte de elementos con escaso beneficio cárnico (Bernáldez y Bernáldez 2008; Bernáldez 2009), es decir, partes anatómicas, como son cañas de las extremidades (metápodos) o los cráneos, en las que la energía consumida en extraer el alimento es superior a la obtenida. El hallazgo de estas partes anatómicas relaciona a este depósito con los de las zonas de despojería de los mataderos actuales (Bernáldez 2009). Sin embargo, la conservación de huesos con beneficio cárnico como tibias o fémures nos indica que hubo consumo de una parte del animal sacrificado.

Algo que hemos observado en las monterías de la Sierra Norte de Sevilla es la acumulación de vísceras, cañas y cabezas después de preparar las piezas cobradas para consu- 


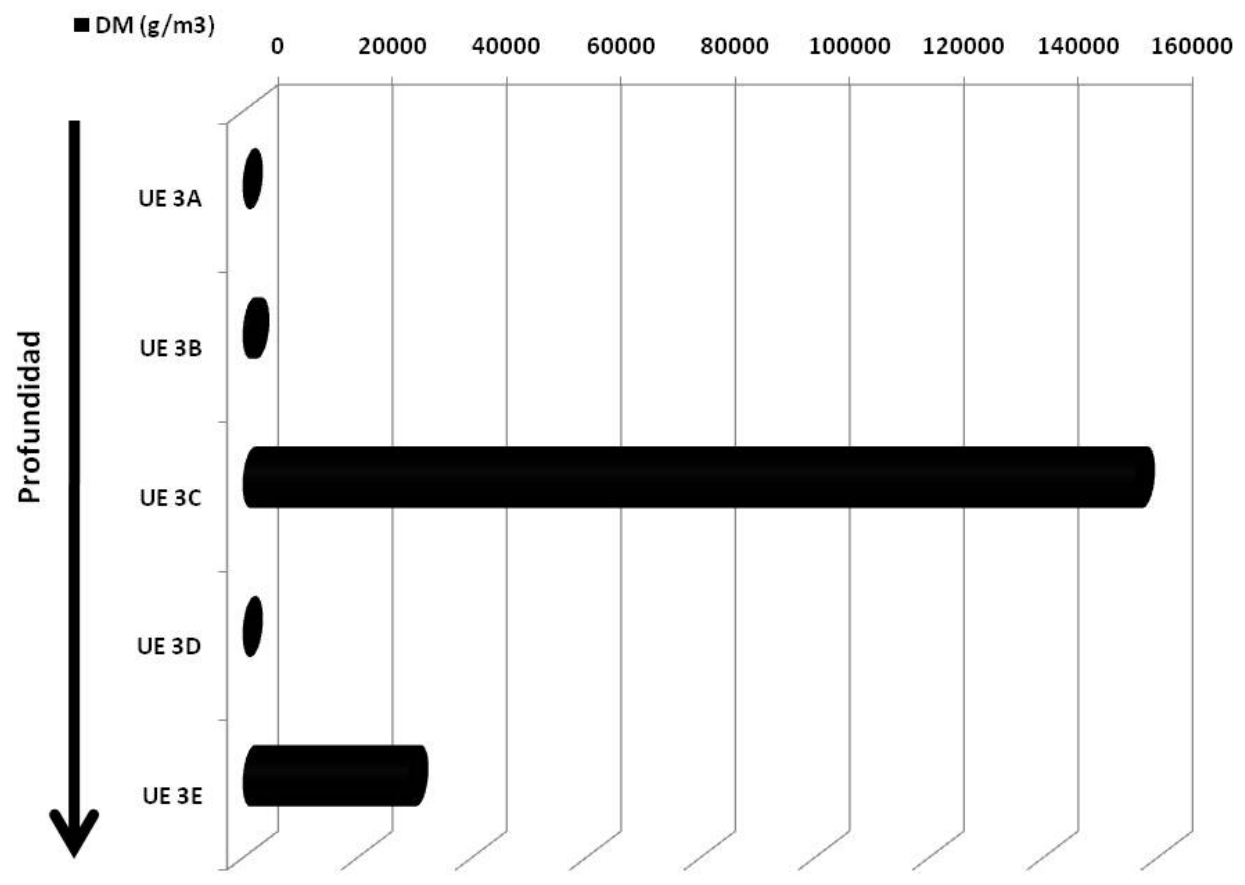

FIGURA 7. Densidad de masa de cada una de las unidades estratigráficas descritas dentro de la estructura intervenida en la UI 9.

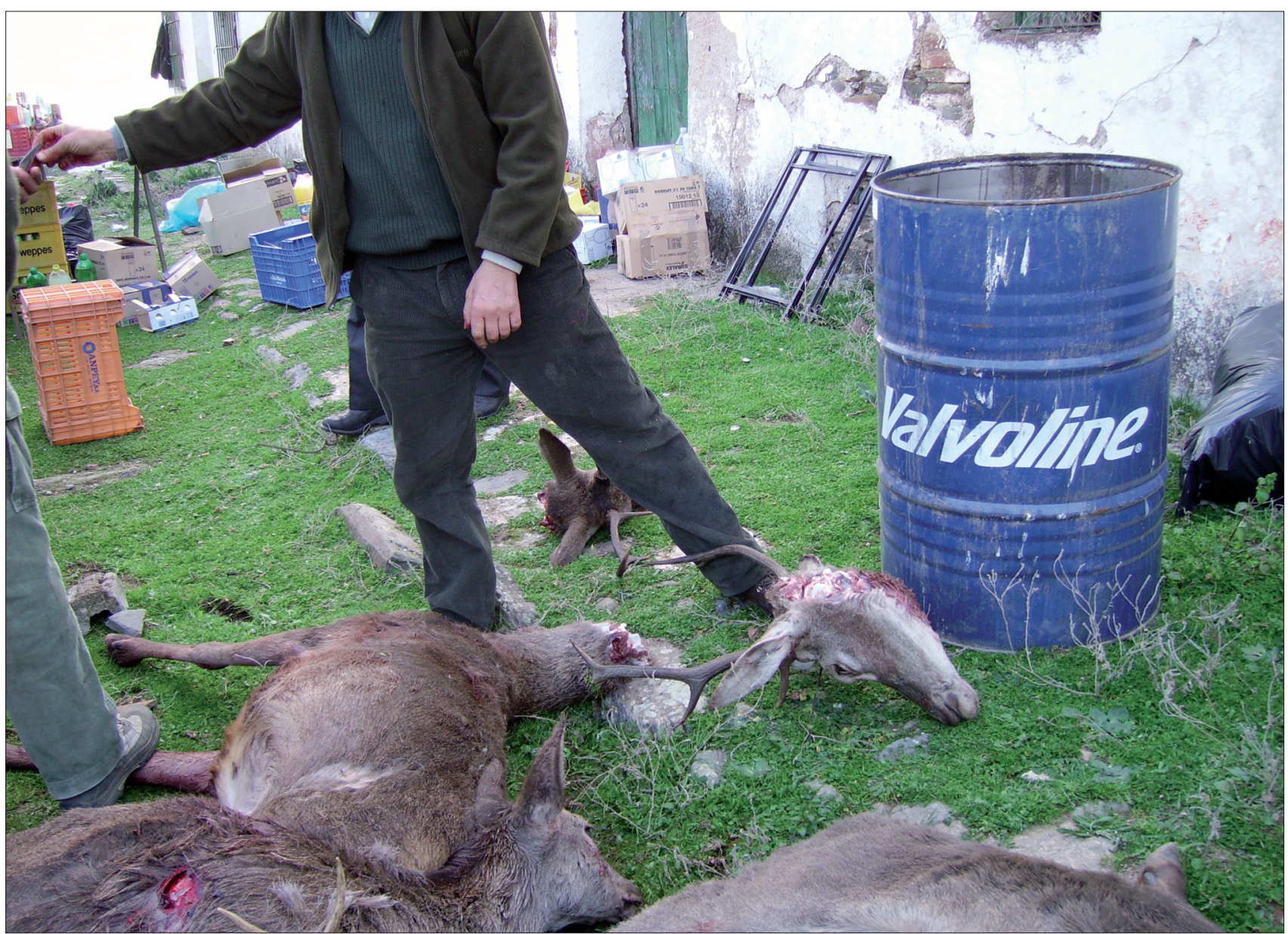

FiguRA 8. Persona preparando un ciervo tras una montería realizada en enero de 2006 en la Sierra Norte de Sevilla. La cabeza aparece cortada a la altura del occipital 


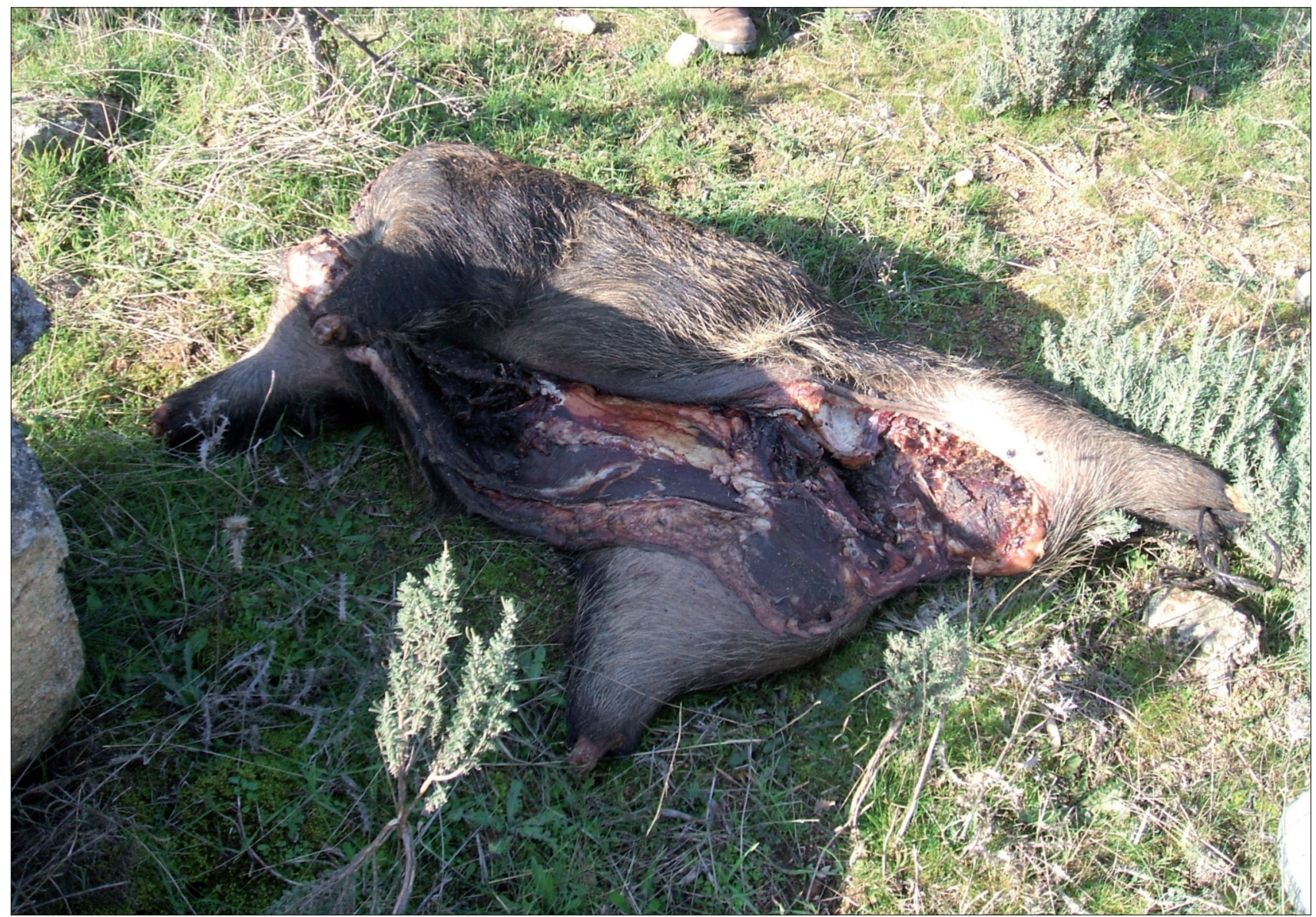

Figura 9. Restos de un jabalí tras despojarlo de las cañas y la cabeza.

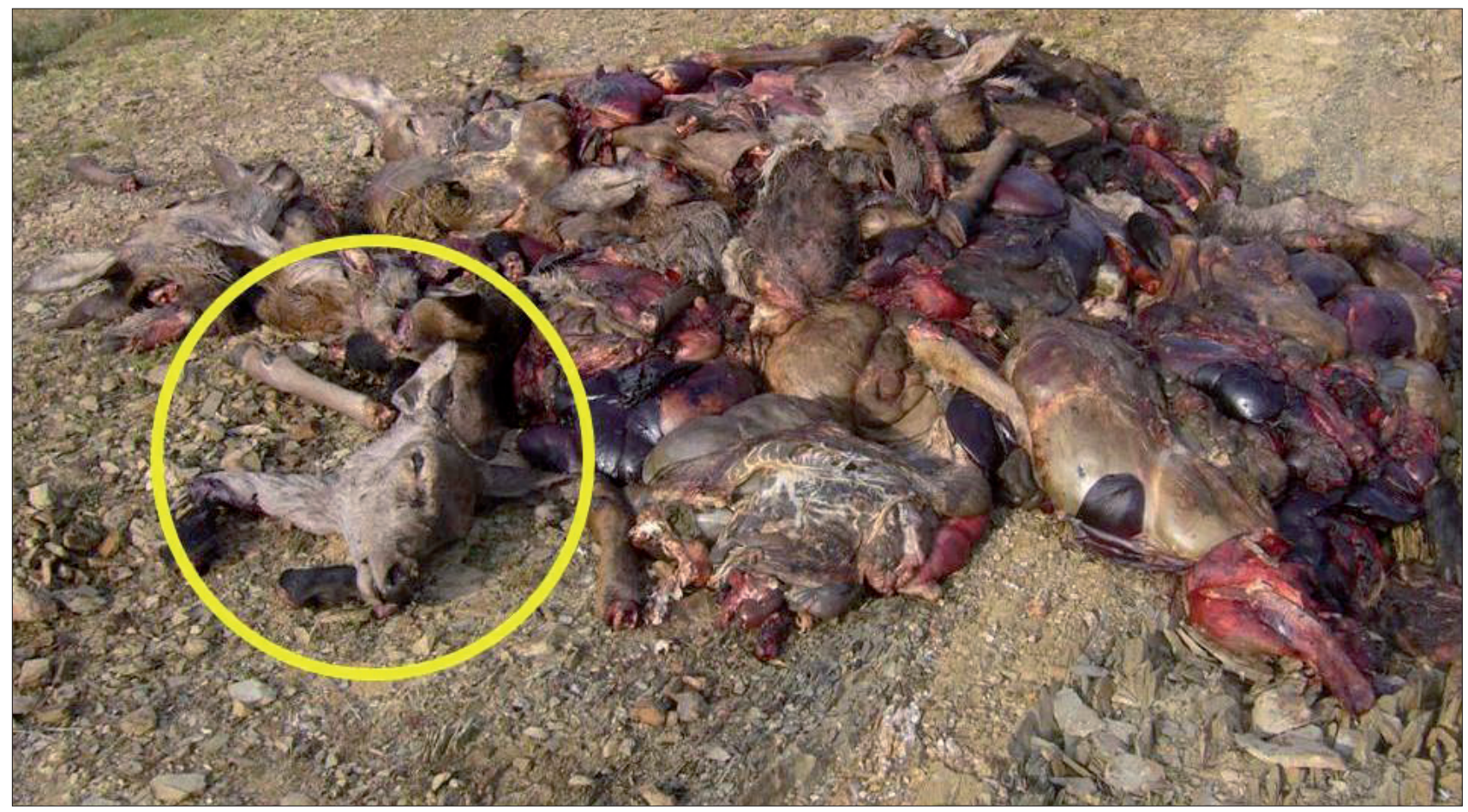

Figura 10. Imagen de una zona de desecho de despojos tras una montería en diciembre de 2006 en la Sierra Norte de Sevilla. Se puede observar entre las vísceras restos de cabeza y de extremidades. 
mirlas, como se puede apreciar en las figuras 8, 9 y 10 (Parque Natural Sierra Norte de Sevilla), actualmente se dejan estos despojos a los buitres como medida de conservación de las grandes especies de aves carroñeras fomentada por la Consejería de Medio Ambiente de la Junta de Andalucía, no creemos que esto mismo ocurriese en otros tiempos.

En cuanto a la actividad cinegética que estos pobladores de "Los Páramos" practicaron podemos afirmar que el rango de edad de la tafocenosis de jabalies podría llevarnos a deducir el carácter domesticado de los suidos si no fuese por la etología de esta especie: son precoces sexualmente, cambian a un pelaje de adulto antes del año y suelen formarse piaras de 3 a 5 individuos (Rosell et al. 2001). El hallazgo de tres jabalies con un año, un año y medio y unos dos años o más, se asemeja a las piaras de jabalies de los actuales ecosistemas mediterráneos, por lo tanto, no es una característica de la domesticación el sacrificio de juveniles, también es una práctica cinegética oportunista (Magnell 2005). Si además, durante los trabajos de investigación bioestratinómica de la Sierra Norte de Sevilla se han encontrado mandíbulas con estas mismas características, juveniles con menos de dos años que fueron abatidos en monterías, tenemos una prueba más de las prácticas cinegéticas que persisten hasta ahora.

Aunque el comienzo de la domesticación puede datarse en torno al 11.000 a. C. en el próximo oriente (Peters y Schmidt 2004), tradicionalmente el Calcolítico ha estado marcado por el auge de la agricultura y la ganadería, sin embargo son muchas las referencias de la presencia de restos de ciervo y jabali en yacimientos en la Península Ibérica (e. g. Díaz del Río et al. 1997; Díaz del Río 2004; Blasco et al. 2007). En el sur encontramos referencias como las de Hernández (1988) y Navas et al. (2008) en la parte oriental o las de Ber- náldez (2009; et al. 2006) en Andalucía occidental. Según Acosta (1995) la cinegética aún poseía cierta importancia en los yacimientos de la Edad del Cobre localizados en cuevas y en asentamientos temporales del S.0. de la Península Ibérica, de hecho en Jordá et al. (1986: 211) se puede leer:

"La caza jugó un papel especial, no tanto en los valles, como en las zonas montañosas y boscosas, como demuestran los altos porcentajes de la misma en las cuevas excavadas. Los niveles calcolíticos de la cueva de la Dehesilla dan especies de ciervo rojo, jabalí, tejón, lince, liebre y conejo. La cueva de Nerja entregó ciervo rojo y jabali, principalmente. En los Castillejos de Montefrío, sorprendentemente, aumenta la caza en el momento de la transición al Calcolítico,..."

Un hecho que afianza la hipótesis de que este depósito sea un lugar de despojo de la cacería es la inexistencia de restos de caprinos y bovinos. En todas las intervenciones arqueológicas estudiadas coetáneas o posteriores aparece un número representativo de ambos grupos zoológicos actualmente domesticados. En "Los Páramos» sólo hallamos restos de suidos, presumiblemente jabalies, y de ciervos que demuestran la práctica cinegética a pie de sierra.

Aún tenemos dudas de por qué se entierran los desechos de la preparación de las presas y del consumo de parte de ellas, en la actualidad ciertas partes sin beneficio cárnico son abandonadas en la superficie para que las aves carroñeras obtengan un alimento adicional, pero estos pobladores enterraron los desechos, ¿cuál era el objetivo? Quizás nuestra próxima publicación demuestre que los escasos huesos enterrados en estos campos de hoyos de la Edad del Cobre nos estén indicando una práctica básica para mantener los nutrientes de los suelos agrícolas: el compostaje.

\section{BIBLIOGRAFIA}

Acosta Martinez, P. 1995: «Las culturas del neolítico y calcolítico en Andalucia Occidental». Espacio, Tiempo y Forma, Serie I, Prehistoria y Arqueología 8: 33-80.

ArenAS, J. M. y CARRASCAL, F. 2004: "Situación medioambiental del corredor verde del Guadiamar 6 años después del vertido de Aznalcóllarn. Ecosistemas: revista científica y técnica de ecología y medio ambiente 13(3): 69-78.

Azorit, C. y Moro, J. 2010: «Jabali (Sus scrofa Linnaeus, 1758)". En J. Santiago y A. López (coord.): Ungulados silvestres de España: biología y tecnologías reproductivas para su conservación y aprovechamiento cinegético. INIA, Ministerio de Ciencia e Innovación. Madrid: 215-240.

BARONE, R. 1999: Anatomie compare des mammifères domestiques. Tome 1 Ostéologie. $4^{\mathrm{a}}$ Edic. Bigot. Paris.

BehrensmeYer, A. K. y BoAz, D. E. D. 1980: «The Recent Bones of Ambosely National Park, Kenya, in Relation to East African Paleobiology" En A. K. Behrensmeyer y A. P. Hills (ed.): Fossils in the Making. University Chicago Press. Chicago: 72-92.

BeHRENSMEYER, A. K. 1978: "Taphonomic and ecologic information from bone weatheringn. Paleobiology 4 (2): 150-162.

Bernáldez SÁnCHEZ, E. (en prensa). «Biostratinomy applied to the inter- pretation of scavenger activity in paleoecosystems». Quaternary International.

- 2010. «Nuevas aportaciones de la paleobiología a la historia de Valencina". Comunicación Congreso Conmemorativo del Descubrimiento del Dolmen de la Pastora (1860-2010). 9-12 de noviembre de 2010. Valencina de la Concepción.

- 2009: Bioestratinomía de macrovertebrados terrestres de Doñana. Inferencias ecológicas en los yacimientos del S.O. de Andalucía. Archaeopress. Oxford.

Bernáldez Sánchez, E.; Garcia-Viñas, E.; Gutiérrez Parra, F.; Ortiz Romero, C.; Bernáldez Sánchez, M.: Ocaña Garcia de Veas, A.; Vázouez Gill, F. J.; Gamero Esteban, M. y Vela Grimaldi, A. 2008: "La Ecología de la Muerte: Bioestratinomía en el Parque Natural de la Sierra Norte de Sevilla». En Consejería de Medio Ambiente Junta de Andalucia (ed.): Investigación científica y conservación en el Parque Natural Sierra Norte de Sevilla. Consejería de Medio Ambiente. Sevilla: 183-209.

Bernáldez SÁnchez, E. y Bernáldez Sánchez, M. 2008: "Ancient and new slaughterhouses: The "Calle Virgenes, 9" medieval archaeological site (Seville)». En J. Aguirre et al. (ed.): Abstracts $3^{\text {rd }}$ Meeting in Taphonomy and Fossilization, (Granada, 2008): 21-22.

Bernáldez Sánchez, E.; Garcia-Viñas, E.; Vázouez Gil, F. J. y Bernáldez SánCHEZ, M. 2006: «Bioestratinomía como herramienta de gestión del medion. Pliocénica 5: 95-104. 
Bernáldez SÁnchez, E. y Bernáldez Sánchez, M. 2003: «Restos óseos del Alfarm. En Tabales, M. A. (coord.): Arqueología y rehabilitación en el Parlamento de Andalucía. Investigaciones arqueológicas en el antiguo Hospital de las Cinco Llagas de Sevilla. Secretaría General del Parlamento de Andalucía. Sevilla: 171-172.

Bernáldez SÁnChez, E. 2002: «Archaeological Garbage Dumping Sites: a new taphonomic approach». En de Renzi et al. (eds.): Current topics on taphonomy and fossilisation. Excmo. Ayuntamiento de Valencia. Valencia: 457-470.

Bernáldez Sánchez, E. y Bernáldez SÁnchez, M. 1999: «La basura orgánica de Lebrija en otros tiempos. Estudio paleobiológico y tafonómico del yacimiento arqueológico de la calle Alcazaba de Lebrija (Sevilla)». Boletín del Instituto Andaluz del Patrimonio Histórico 32: 134-150.

BLAnCO, J. C. 1998: Mamíferos de España II. Geoplaneta. Barcelona.

Blasco, C.; Dellbes, G.; BaenA, J.; LIesAu, C. y Rios, P. 2007: "El poblado calcolítico de Camino de las Yeseras (San Fernando de Henares, Madrid): Un escenario favorable para el estudio de la incidencia campaniforme en el interior peninsular». Trabajos de Prehistoria 64 (1): 151-163.

Cabrero Garcia, R., Bernáldez Sánchez, E., Gómez Murga, E. y Bernáldez SÁNCHEZ, M. 2006: "Amarguillo II: arqueología, Paleobiologia y tafonomian. Pliocénica 5: 83-94.

DAVIS, SIMON, J. M. 1989: La arqueología de los animales. Bellaterra. Barcelona.

Díaz-Del Río, P. 2004: "Copper Age ditched enclosures in Central Iberia». Oxford Journal of Archaeology 23 (2): 107-121.

Diaz-Del Rio, P.; Consuegra, S.; Peña Chocarro, L.; Márouez, B.; Sampedro, C.; Moreno, R.; AlBeRtINI, D. y PINo, B. 1997: «Paisajes agrarios prehistóricos en la meseta peninsular: El caso de "Las Matillas" (Alcalá de Henares, Madrid)». Trabajos de Prehistoria 54 (2): 93-111.

ÉTIENNE, P. 2004: El Jabalí. Omega. Barcelona.

FERNÁNDEZ-LóPEZ, S. R. 2006: «Taphonomic alteration and evolutionary taphonomy». Journal of taphonomy 4 (3): 111-142.

FERNÁNDEZ-LLARIO, P. 1996: Ecología del jabalí en Doñana: parámetros reproductivos e impacto ambiental. Tesis doctoral. Universidad de Extremadura, Cáceres.

Garde, J. J.; Fernández-Santos, M. R.; Soler, A. J.; Esteso, M. C., MarotoMorales, A.; Garcia-Álvarez, 0.; García-Diaz, A. J.; Ortiz, J. A. y RaMÓN, M. 2010: "Ciervo ibérico (Cervus elaphus hispanicus Hilzheimer, 1909)». En J. Santiago y A. López (coord.): Ungulados silvestres de España: biología y tecnologías reproductivas para su conservación y aprovechamiento cinegético. INIA, Ministerio de Ciencia e Innovación. Madrid: 157-178.

Hunt ORTIZ, M. A. 2003: «Intervención arqueológica en el coto minero de Aznalcóllar (Sevilla): El yacimiento Calcolítico de los Páramos y la necrópolis de Cistas de la Mesan. Anuario arqueológico de Andalucía/ 2000. vol. 3: 1196-1202.

HERNÁNDEZ GoNZALO, A. 1988: Evolución interna y factores ambientales en la interpretación del calcolítico del suroeste de la Península lbérica. Una revisión crítica. Tesis Doctoral. Universidad Complutense de Madrid.

Jordá Cerdá, F.; Pellicer Catalán, M.; Acosta Martinez, P.; y Almagro-GorBEA, M. 1986: Historia de España 1. Prehistoria. Gredos. Madrid.

MAd0Z, P. 1850: Diccionario geográfico-estadistico-histórico de España: Sevilla. Ambito ediciones. Valladolid.

MAGNELL, 0. 2005: "Harvesting Wild Boar -a study of prey choice by hunters during the Mesolithic in South Scandinavia by analysis of age and sex structures in faunal remains". Archaeofauna 14: 2741.

Ministerio de Medio AmBiente. 2004. Censos de ungulados silvestres (ciervos y gamos). Área de Conservación. Doñana.

Montón SUBíAS, S. 1999: "Determinación osteológica. Primera aproximación al estado de la evidencian. En Castro Martínez, P.V. et al. (eds.): Proyecto Gatas 2. La dinámica arqueológica de la ocupación prehistórica. Consejería de Cultura de la Junta de Andalucía. Sevilla: $320-324$

NAVAS, E.; EsQuivel, J. A. y MolinA, F. 2008: «Butchering patterns and spatial distribution of faunal animal remains consumed at the Los MiIlares Chalcolithic settlement (Santa Fé de Mondújar, Almería, Spain)». Oxford Journal of Archaeology 27 (4): 325-339.

Peters, J. y SCHMIDT, K. 2004: "Animals in the symbolic world of Pre-Pottery Neolithic Göbekli Tepe, south-eastern Turkey: A preliminary assessment». Anthropozoologica 39 (1): 179-218.

POPESKO, P. 1998: Atlas de anatomía topográfica de los animales domésticos. Tomos I, II y III. MASSON.

RenZI DE, M.; MARTINELL, J. y ReguANT, S. 1975: «Bioestratigrafía, tafonomía y paleoecologían. Acta Geológica Hispánica 2: 80-86.

Rosell, C., Fernández-Llario, P. y HerRero, J. 2001: "El jabali (Sus scrofa Linnaeus, 1758)». Galemys 13 (2): 1-25

SCHMID, E. 1972: Atlas of animal bones. For Prehistorians, Archaeologists and Quaternary Geologists. ELSEVIER PUBLISHING COMPANY. Amsterdam. WILKENS, B: 2003. Archeozoologia. Universita'degli studi di Sassari. DVD. 